\title{
A LATE PERMIAN FOSSIL HORSESHOE CRAB (PALEOLIMULUS: XIPHOSURA) FROM POATINA, GREAT WESTERN TIERS, TASMANIA
}

\author{
by D. L. Ewington, M. J. Clarke and M. R. Banks
}

(with one text-figure and one plate)

\begin{abstract}
EWINGTON, D.L., CLARKE, M.J. \& BANKS, M.R., 1989 (31:x): A Late Permian fossil horseshoe crab (Paleolimulus: Xiphosura) from Poatina, Great Western Tiers, Tasmania. Pap. Proc. R. Soc. Tasm. 123: 127-131. https://doi.org/10.26749/rstpp.123.127 ISSN 0080-4703. Launceston College, Paterson Street, Launceston, Tasmania 7250 (DLE); Geological Survey of Tasmania, PO Box 56, Rosny Park 7018 (MJC); Geology Department, University of Tasmania, GPO Box 252C, Hobart 7001 (MRB) Australia.
\end{abstract}

The xiphosuran Paleolimulus Dunbar, 1923 is recorded from the Late Permian (Chhidruan) Jackey Shale at Poatina, $41^{\circ} 48^{\prime} 05^{\prime \prime S} 146^{\circ} 53^{\prime} 06^{\prime \prime E}$. This is the first record of the genus in both Tasmania and the Southem Hemisphere, and extends its distribution to rocks deposited in a high latitude, cold-water environment.

Key Words: Late Permian, cold-water, xiphosuran, Tasmania.

\section{INTRODUCTION}

The purpose of this brief communication is to record the discovery of a specimen of the horseshoe crab Paleolimulus (Merostomata, Xiphosura) in the Jackey Shale at Poatina. The specimen was found by David Castle, a student at Launceston College, whilst on a geological excursion to Poatina led by the senior author. The specimen was located in the upper part of the Jackey Shale about $3 \mathrm{~m}$ below the base of the overlying massive- and cross-bedded, cliffforming, quartz sandstone of the Ross Formation exposed alongside the Poatina Highway at DP 49055371 (Grid zone 55G Australian Metric Grid), $41^{\circ} 48^{\prime} 05^{\prime \prime S} 146^{\circ} 53^{\prime} 06^{\prime \prime} \mathrm{E}$.

\section{STRATIGRAPHY AND AGE}

The Jackey Shale is the lowermost stratigraphic unit of the non-marine Upper Parmeener Supergroup. It conformably overlies the youngest rocks (Bogan Gap Group) of the glacio-marine Lower Parmeener Supergroup and is, in turn, overlain conformably by massive- and crossbedded, freshwater, quartz sandstone of the Ross Formation. At Poatina, the Bogan Gap Group is essentially unfossiliferous except for worm burrows and other trace fossils, but about $25 \mathrm{~km}$ to the southeast, at Lake River, a fauna indicative of the Echinalosia ovalis Zone (Late Lymingtonian =
Kazanian) occurs close to the Palmer Sandstone (within the lower half of the Bogan Gap Group). Associated microfloras include the palynomorph Didecitriletes ericianus, which indicates an age no older than lower Stage 5b of the eastern Australian palynological zonal scheme (Kemp et al. 1977). To date, the only macrofossils recorded from the Jackey Shale and correlative beds are the abundant plants Glossopteris, Gangamopteris, Vertebraria, Phyllotheca and Schizoneura, and these indicate a generalised Late Permian age. Associated microfloras are more definitive, however, and can be assigned to the Protohaploxypinus microcorpus Zone of Late Permian (Chhidruan) age (Forsyth 1984). The upper part of the overlying Ross Formation and correlative beds yield vertebrate faunas and both macro- and microfloral assemblages of early Triassic age (Forsyth 1989).

\section{DESCRIPTION}

This specimen (UTGD 123979) is the internal mould in siltstone of the carapace of the prosoma and opisthosoma, still connected (fig. 1; plate 1A). The opisthosoma lacks the telson and has no posterior moveable segment. The right-hand side of the prosoma is somewhat laterally compressed at the back. Some grooves in the mould are interpreted as traces of the appendages.

The prosoma is $16.9 \mathrm{~mm}$ long (axially), $23.4 \mathrm{~mm}$ wide (L:W::0.72:1). (All measurements sagittally 


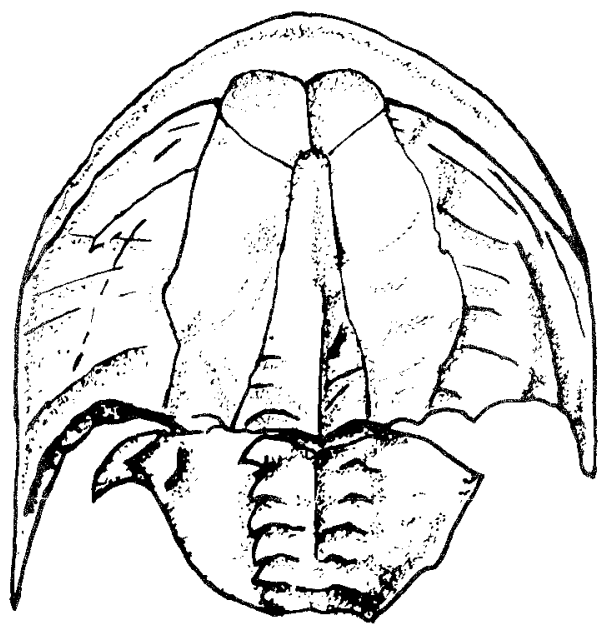

FIG. I-Paleolimulus sp. $\times 2.5$. UTGD 123979, Jackey Shale, Upper Permian, Poatina, Tasmania. Drawn by D.M. Banks.

are taken parallel to the axis and from the intersection of the axis and the anterior margin of the occipital furrow (the reference point, "r.p."), transversely from the axis; the width quoted was obtained by doubling the width of the left-hand, undistorted side.) The margin is uniformly curved in plan and forms a parabola. The outer margin of the genal angle diverges slightly outwards (about $4^{\circ}$ ) from the general curve of the lateral margin. The posterior margin curves gently forwards to a point $8.2 \mathrm{~mm}$ from the axis and $1.1 \mathrm{~mm}$ in front of "r.p.". From that point it curves sharply back to form the inner margin of the genal spine. The spine tip is $7.2 \mathrm{~mm}$ behind "r.p.", giving a spine length of $8.3 \mathrm{~mm}$. Thus the spine is about 0.49 the axial length of the prosoma. The raised, keeled, cardiac lobe is $6.2 \mathrm{~mm}$ wide posteriorly and $11 \mathrm{~mm}$ long. The axial furrows converge forward from the posterior margin to about $3 \mathrm{~mm}$ in front of "r.p." before becoming slightly convex outwards to a point $7.1 \mathrm{~mm}$ in front of "r.p.". For the front $3.4 \mathrm{~mm}$, the cardiac lobe is almost parallel-sided and only $1.25 \mathrm{~mm}$ wide. A neck furrow and three, possibly four, furrows are visible in the anteriorly convergent part of this lobe, only the neck furrow being complete. Little can be made of the interophthalmic region. A low, narrow ridge projects forward in the mid-line from the front of the cardiac lobe to meet the re-entrant between the left and right opthalmic ridges. From just behind the front of the cardiac lobe a groove on each side runs anterolaterally to the ophthalmic ridge which it cuts $12 \mathrm{~mm}$ in front of "r.p.". At the ridge it turns posterolaterally to converge in a gentle curve towards the lateral margin which it meets $8.1 \mathrm{~mm}$ in front of "r.p.". This groove defines the posterior edge of the doublure. The ophthalmic ridges differ a little from left to right side because of the deformation. The left-hand ridge commences posteriorly $6.1 \mathrm{~mm}$ from "r.p." and runs more-orless straight forward for $5 \mathrm{~mm}$; then its course is interrupted by a small, outwardly convex bump $1.3 \mathrm{~mm}$ long and a little less than $1 \mathrm{~mm}$ broad, which is probably the compound eye. In front of the bump the ridge runs forward and a little inward to about $3.2 \mathrm{~mm}$ in front of the cardiac lobe before curving axially, uniformly and gently to meet the other limb of the ophthalmic ridge $2.5 \mathrm{~mm}$ in front of the cardiac lobe. The right-hand ridge is gently convex outwards behind the compound eye but is otherwise similar to that on the left. The fields between the ophthalmic ridges and the lateral margins of the prosoma show structures of two types (plate 1B). The first of these types consist of four grooves, each with a sharp anterior slope and a gentle posterior one. The grooves arise from or close to the ophthalmic ridge, the anterior three just in front of, opposite and just behind the compound eye, the posteriormost one from about halfway between the compound eye and the posterior margin. The front one runs to the submarginal groove, almost at right angles to the axis, more posterior ones fanning so that the posteriormost curves outwards and backwards, almost parallel to the inner margin of the genal spine, and ends at about the beginning of the spine. Of these grooves the posterior is the most marked. The description of these grooves is based on the left-hand side, the right not being clear enough. The second type of structure in the area outside the ophthalmic ridges consists of narrow, well-defined grooves gently curved posterolaterally. These originate close to the ophthalmic ridge and run approximately parallel to the margin of the doublure. Successive grooves are progressively longer, the anteriormost being only about $1.1 \mathrm{~mm}$ long, the most posterior between three and four times as long and terminating posteriorly close to the hindmost fanning groove. Three, perhaps four, such grooves can be seen, each groove starting axially and anteriorly from the posterior end of the one in front of it and possibly connected to it by a short, linking groove. The overall arrangement appears zigzag. A somewhat similar arrangement on the right-hand side is distorted by deformation. These grooves are interpreted as traces of the 


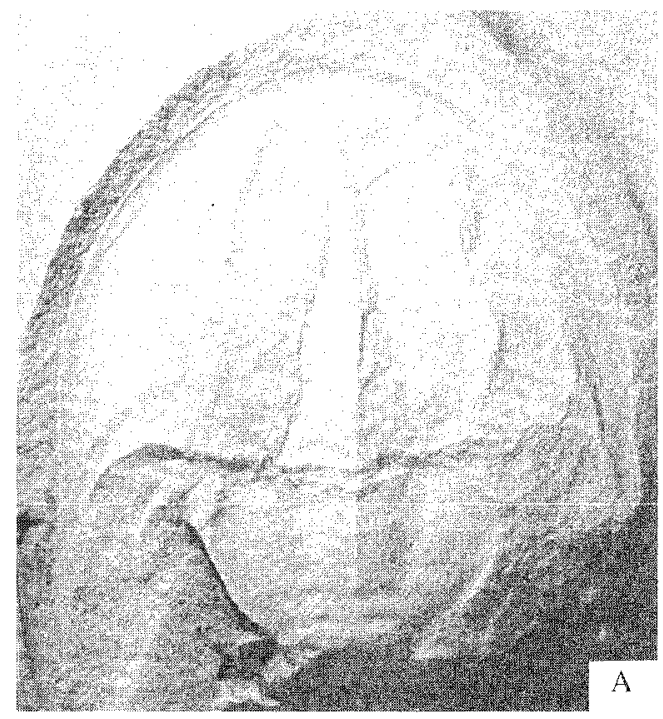

PLATE I

Paleolimulus $s p . \times 2.5$ approx.: (A) the obscure radial markings on the lateral portions of the prosoma represent impressions of the ventral appendages; $(B)$ left-hand side of prosoma showing the impressions of the ventral appendages more clearly.

appendages. The lateral fields show a submarginal furrow most noticeable anteriorly and anterolaterally. The margin itself has a narrow, low brim representing a shallow groove in the original carapace.

The opisthosoma has a maximum width just behind the front margin of $12.3 \mathrm{~mm}$, i.e. just over half of that of the prosoma, and is $7 \mathrm{~mm}$ long, although not all is preserved. The front margin is almost straight in the axial region and remains so on the left-hand side as far out as the base of a spine. On the right-hand side it curves down and back with an angular lateral termination. The lateral margins are smooth, except for the spine and angulation, and gently curved. The opisthosoma is approximately semicircular in outline. On the right-hand side is a low, rather narrow rim and on both sides evidence of a submarginal furrow, broad and shallow. The axis is $6.4 \mathrm{~mm}$ wide anteriorly and narrows to about $5 \mathrm{~mm}$ at the posterior end, thus being almost parallel sided. Seven pits occur in the axial furrows on each side and, in the case of the second, fifth and sixth, mark the ends of grooves which cross the axis. The other pits have either short or no grooves associated with

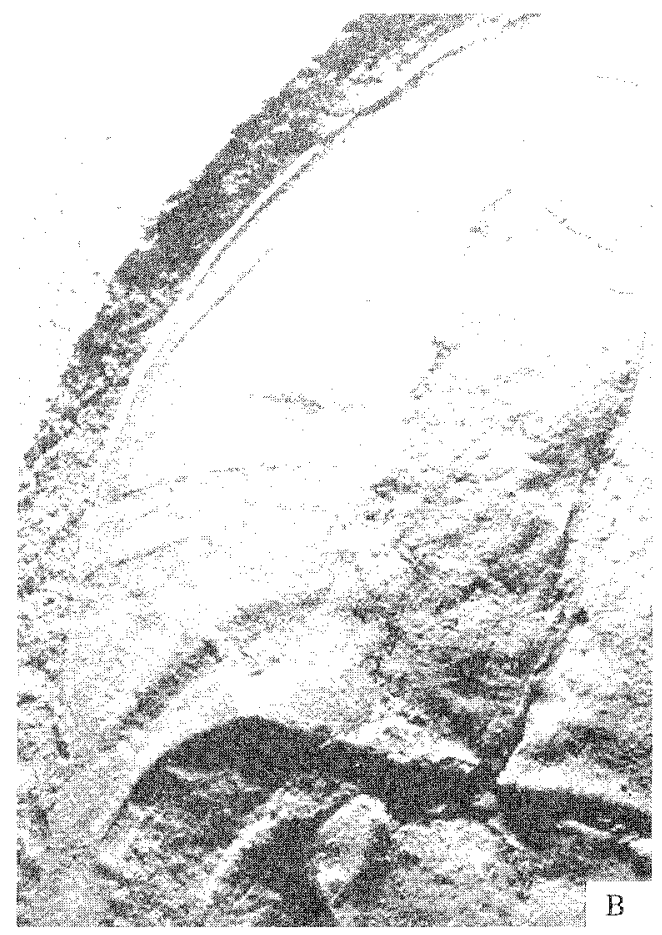

them. The pits are probably impressions of apodemes. No moveable spines are clearly exposed, unless it be that the left anterior spine is such. This latter spine, however, may be an anterolateral free spine. No moveable segment occurs in the opisthosoma as preserved, nor is the telson preserved.

\section{COMPARISONS}

The specimen is comparable in many respects to Paleolimulus avitus Dunbar, 1923 from the Lower Permian of North America, and a reasonably confident assignment to that genus, to Limulitella sensu Gall, 1971 or a closely related new genus, is warranted. Similarities include the general size and shape, the ophthalmic ridges which meet in front of the cardiac lobe, and the annulated opisthosomal axis. All these features are diagnostic of the family Paleolimulidae Raymond, 1944. The Tasmanian form differs, however, from the North American and some other species in that the prosoma is parabolic, not semicircular, and about twice as long as the opisthosoma, that the interophthalmic region 
shows only obscure traces of lobation and that lobation in general is less well developed than in $P$. avitus; also, the ophthalmic ridges extend closer to the anterior margin of the prosoma, which is marked by a well-developed doublure. This latter feature is not evident in $P$. avitus in which, however, its presence may be inferred since it is present in most limuloids. Only one lateral opisthosomal spine is visible on the Tasmanian specimen, which may be an anterolateral free spine. Rather unusually, its opisthosomal axis maintains an almost even width throughout its length, in contrast to the distinct posterior taper in most limuloids. Another North American species, Paleolimulus signatus (Beecher), from the PermoCarboniferous Fort Riley Limestone, Kansas (Dunbar 1923: fig. 8), resembles the Tasmanian form in its anteriorly produced cardiac lobe and ophthalmic ridges but, again, shows well marked lobation in the interophthalmic regions.

Hauschke \& Wilde (1987: 88) used the relationship of the inner margin of the genal spine to the lateral margin of the opisthosoma to differentiate Paleolimulus from Limulitella. The genal spine in Limulitella is distinctly triangular, wide anteriorly with a straight inner margin and extending axially as far as the anterolateral corner of the opisthosoma, with the lateral margin of which the inner margin of the genal spine makes an acute angle. In the Tasmanian specimen, the genal spine is less distinctly triangular, has a curved inner margin, is comparatively narrow anteriorly and commences a millimetre or so outside the anterolateral corner of the opisthosoma. On the basis of these characters, this specimen is closer to Paleolimulus than to Limulitella. It differs from Limulitella bronni (Schimper, 1853), type species of Limulitella Stormer, 1952 in the outline of the prosoma, in the width, shape and axial extent of the genal spine and in the relative lengths of the prosoma and opisthosoma. Further, the opisthosoma of Limulitella has lateral margins with indentations not evident in the Tasmanian specimen (pace Gall 1971). In view of these differences from $P$. avitus on the one hand and Limulitella on the other, the Tasmanian material may well be a new genus, but the authors consider it inadvisable to base a new genus on a single, incomplete, internal mould.

Dubbolimulus peetae Pickett, 1984, from the Middle Triassic of the Sydney Basin, New South Wales, is broadly similar in size and shape, but the prosoma is proportionately shorter and wider, the pre-ocular ridges do not meet in front of the cardiac lobe, the eyes are more posteriorly placed, the opisthosoma lacks lateral spines, and the opisthosomal axis is not annulated. The present authors do not agree with the synonymy of Dubbolimulus and Paleolimulus as advocated by Hauschke \& Wilde (1987). Austrolimulus fletcheri Riek, 1955, also from the Triassic of the Sydney Basin, with its long, laterally directed genal spines and other features, is quite distinct.

\section{SIGNIFICANCE}

Fossil Upper Palaeozoic (and other) xiphosurans are generally rare. They are mostly known from warm-climate, non-marine Upper Carboniferous coal measure sequences in Europe, and Permian rocks in North America. The present Tasmanian example, the first record of the genus Paleolimulus from the Southern Hemisphere, is from rocks deposited in a freshwater, fluvial environment, and thus extends the distribution of the genus to highlatitude $\left(75-80^{\circ} \mathrm{S}\right)$, cold-climate regimes which then prevailed, following the severe Late Palaeozoic glaciation of the Tasmanian region and elsewhere in Gondwana. The other undoubted Australian xiphosurans are Austrolimulus and Dubbolimulus, both from the Triassic of the Sydney Basin, New South Wales, and Victalimulus from the Lower Cretaceous of Victoria (Riek \& Gill 1971). Pincombella belmontensis Chapman, 1932, previously recorded as the sole Permian xiphosuran from Australia, is an incomplete hemipteran insect (Pickett 1984).

\section{ACKNOWLEDGEMENTS}

D.L. Ewington publishes with the permission of the Education Department, Tasmania, and M.J. Clarke with the permission of the Geological Survey of Tasmania. Mr Michael Seitz helped with the translation of relevant passages in Hauschke \& Wilde's paper. The authors benefited from comments by Dr J.W. Pickett.

\section{REFERENCES}

Chapman, F, 1932: Two new Australian fossil kingcrabs. Proc. R. Soc. Vict. N.S. 44: 100-102.

Dunbar, C.A., 1923: Kansas Permian insects. Part 2. Paleolimulus, a new genus of Paleozoic Xiphosura, with notes on other genera. Am. J. Sci. Ser. 5(5): $443-454$

Forsyth, S.M., 1984: Oatlands. Geol. Atlas 1:50 000 ser. Explan. Rep. Zone 7, Sheet 68 (8313S). Tasm. Dep. Mines.: 1-182. 
Forsyth, S.M., 1989: Upper Parmeener Supergroup. In Burrett, C.F. \& Martin, E.L. (Eds): GEOLOGY AND MINERAL RESOURCES OF TASMANIA. Geol. SOC. Aust. Spec. Publ. 15: 309-335.

GaLL, J.C., 1971: Faunes et paysages du grès à Voltzia du Nord des Vosges. Essai paléoécologique sur le Bundsandstein Superieur. Mem. Serv. Carte. geol. Als. Lorr. 34: 35-36.

Hauschke, N. \& Wrlde, V., 1987: Paleolimulus fuchsbergensis (Xiphosura, Merostomata) aus der oberen Trias von Nordwestdeutschland, mit einer Ubersicht zur Systematik und Verbreitung rezenter Limuliden. Palaeont. Z. 61: 87-108.

Kemp, E.M., Balme, B.E., Helby, R.J., Kyle, R.A., Playford, G.E. \& Price, P.L., 1977: Carboniferous and Permian palynostratigraphy in Australia and
Antarctica. B.M.R. J. Aust. Geol. Geophys. 2: 177-208.

Pickett, J.W., 1984. A new freshwater limuloid from the Middle Triassic of New South Wales. Palaeontology 27: 609-621.

Raymond, P.E., 1944: Late Paleozoic Xiphosurans. Bull. Mus. comp. Zool. Harv. 94: 475-508.

RiEk, E.F., 1955: A new xiphosuran from the Triassic sediments at Brookvale, New South Wales. Rec. Aust. Mus. 23: 281-282.

RieK, E.F. \& Gill, E.D., 1971: A new xiphosuran genus from Lower Cretaceous freshwater sediments at Koonwarra, Victoria, Australia. Palaeontology 14: 206-210.

(accepted 12 May 1989) 